У, $\triangle \mathrm{K}$ 658.310.9:35.08

ББК 65.291.6+67.401.02

DOI 10.22394/1682-2358-2021-1-39-47

A.V. Baranov, Deputy Director of the South Russian Institute of Management, Branch of the Russian Presidential Academy of National Economy and Public Administration

O.V. Kotlyarova, Candidate of Sciences (Philology), Docent of the Social Disciplines and Humanities Department, Vladimir Branch of the Russian Presidential Academy of National Economy and Public Administration

\section{PROFESSIONAL \\ STANDARD \\ DEVELOPMENT \\ FOR A \\ MULTIFUNCTIONAL \\ PUBLIC SERVICES \\ CENTER EMPLOYEE \\ IN CONDITIONS \\ OF DEMOCRATIC CONTROL}

Results of a survey of multifunctional public services centers employees aimed at identifying the factors that determine the professional standard of MPSC specialists are analyzed. According to the authors, democratic control in the process of assessing the quality of state and municipal services is implemented not only by monitoring the satisfaction of citizens, but also as a result of an objective assessment by MPSC specialists of the quality of performing their own professional duties.

Key words and word-combinations: democratic control, professional standard of the MPSC employees, self-assessment method.
A.В. Баранов, заместитель директора Южно-российского института управления - филиала Российской академии народного хозяйства и государственной служби при Президенте РФ (email:bav.skags@gmail.com)

O.B. Kотлярова, кандидат филологиеских наук, дочент кафедри сочиально-гуманитарньхх дисииплин Владимирского филиала Российской академии народного хозяйства и государственной службь при Президенте РФ (eтаil: olya-apriori@yandex.ru)

\section{PАЗРАБОТКА ПРОФЕССИОНААЬНОГО СТАНААРТА СОТРУАНИКА МНОГОФУНКЦИОНААЬНОГО ЦЕНТРА В УСАОВИЯХ АЕМОКРАТИЧЕСКОГО КОНТРО $Я$}

Аннотация. Анализируются результаты опроса сотрудников многофункциональных центров предоставления государственных и муниципальных услуг, направленного на выявление факторов, определяющих профессиональный стандарт специалистов МФЦ. По мнению авторов, демократический контроль в процессе оценки качества предоставления государственных и муниципальных услуг реализуется не только посредством мониторинга удовлетворенности граждан, но и вследствие объективной оценки специалистов МФЦ качества выполнения собственных профессиональных обязанностей.

Ключевые слова и словосочетания: демократический контроль, профессиональный стандарт сотрудника МФЦ, метод самооценки. 
$\Gamma$

ражданское общество в качестве политического явления предопредемяет функционирование демократического контроля наА органами власти и, в частности, наА процессами качественного и своевременного предоставления государственных услуг.

Аемократический контроль и демократия в целом ограничиваются ценностными ориентирами гражданского общества, которыми Амя граждан Российской Федерации являются свобода выбора, приоритет мичности, соблюдение гражданских прав, возможность активного влияния на политические процессы.

Аемократический контроль подразумевает не только приоритет свободы гражданского общества и власти народа, он определяется взаимообусмовленностью правительства и общества, степенью доверия граждан по отношению к действиям правительства. Аемократический контроль ориентирован на нужды народа. Основами системы демократических џенностей явмяются понятия свободы, прав человека и доверительных властных взаимоотношений.

Аемократический контроль не может осуществляться без создания прозрачной, открыто функционирующей платформы предоставления государственных услуг. Такой платформой, объединяющей деятельность органов власти и нужды гражданского общества, стало пространство многофункциональных центров предоставления государственных и муниципальных ускуг.

Проверка эффективности функционирования органов власти, а значит, и осуществление объективного демократического контроля, определяется прежде всего процентом удовлетворенности гражАан, обратившихся за услугами в многофункциональный центр. В связи с этим на первый план выходит степень активности гражданского общества в осуществлении демократического контроля. Иными словами, значимы желание и активность граждан осуществлять проџессы контроля качества предоставления государственных и муниципальных услуг. Чем масштабнее и объективнее данные, демонстрирующие общественное мнение, тем интенсивнее проџесс демократического контроля деятельности властных структур. Отметим, что неотъемлемой составляющей объективного мнения о качестве предоставляемых государственных и муниципальных услуг является оџенка своей работы самих специалистов многофункциональных џентров (МФЦ), которые знают проблемы, замедляющие процесс предоставления услуг «изнутри», оценивают уровень собственного профессионального развития и качество функционирования системы многофункциональных центров в целом.

Понятие Аемократического контроля в контексте данной публикации применяется к оџенке специалистами МФЦ качества предоставления усмуг, прежде всего к самооценке компетентностного потенџиала их сотруА- 
ников, которые осуществляют профессиональную деятельность на периферии политических институтов гражданского общества и органов власти. В сознании граждан они явмяются опосредованными преАставитемями властных структур и формируют общественное мнение об эффективности работы государственных органов.

Основная цель совершенствования системы предоставления государственных услуг населению заключается в их кастомизаџии и персонализации, то есть ориентаџии на индивидуаАьные потребности и нужды конкретных граждан и организаџий. ОАнако существует множество негативных факторов, препятствующих улучшению качества обслуживания в системе МФЦ.

Анализ актуальной научной митературы позволяет выявить социальноэкономические, управленческие, политические и другие барьеры, затрудняющие проџессы кастомизации и персонализации предоставления госуАарственных и муниципальных услуг для российских граждан.

Многие исследователи в сфере государственного управления (В.А. Белый, П.В. Смирнова, А.В. Чугунов [1] ; Е.Н. Малик, М.В. ШеАий, Б.В. Пикалов [2] ) отмечают проблемы развития нового государственного менеАжмента, обладающего преимуществами интерактивного взаимодействия органов власти и граждан через расширение деятельности госпорталов, многофункциональных центров, государственных автоматизированных систем. Такие сложности обусловлены ускоренными изменениями в объективной реальности, в том числе соџиально-экономическими и демографические усмовиями пандемии.

Цифровизаџия государственного управления в целом и системы предоставления государственных услуг в частности также позволяет опреАелить аспекты, усложняющие процесс персонализации предоставления государственных ускуг. Цифровые трансформационные проџессы в сфере государственного управления как этапы развития современного российского общества, сопровождаемые развитием информаџионных технологий, внеАрением зарубежных и отечественных передовых цифровых практик, получением удаленных услуг и связанных с ними издержек, обсуждаются в исследованиях В.Н. Южакова [3], Ю.Г. Шведова [4]. Цифровизация системы многофункџиональных центров предоставления государственных и муниципальных услуг рассматривается в рамках конџепции бережкивых инноваций [5] .

Особую значимость приобретают факторы, влияющие на востребован-

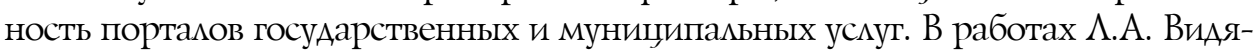
совой, А.В. Чугунова [6] , Е.А. Филимоновой [7] большое внимание удемяется дифференциации и анализу специфики функционирования федеральных и региональных порталов, обсуждаются конџепџии диффузий инноваций.

Безусловно, проблема кастомизации и персонацизации предоставмения государственных и муниџипальных услуг связана с уровнем ка- 
чества предоставления информации о государственных услугах населению. В связи с этим в ракурсе исследовательских интересов (работы А.В. Баранова, А.В. Тагаева, О.А. Ивлевой, О.В. Котмяровой [8] ; В.В. Кваниной, Е.А. Громовой, А.В. Спиридоновой [9] ; В.Н. Южакова, Е.И. Аобролюбовой, В.А. Мау, А.Н. Покида [10] ) оказываются такие вопросы, как полноџенность предоставцяемой населению информаџии, ее доступность, Аогичность, понятность и открытость.

Настоящая публикаџия находится в рамках исследования, реализованного преАставителями Южно-Российского института управления - фимиала РАНХиГС в ходе опроса, проведенного среди сотрудников центров «Мои Аокументы» с целью разработки профессионального стандарта специалиста многофункционального центра предоставления государственных и муниципальных ускуг. Необходимость разработки профессионального стандарта специалиста МФЦ как инновационного способа опредемения квалификации сотрудника уже рассматривалась ранее [11]. Аальнейшее исследование, направленное на разработку профессионального стандарта, на наш взгляА, связано с включением факторов, выделяемых самими сотрудниками МФЦ в качестве наиболее значимых.

Разработка профессионального стандарта реализована при помощи методологии самооџенки сотрудников МФЦ, что в совокупности с анацизом проџента удовлетворённости граждан предоставлением услуг в МФЦ решает задачу полноценного демократического контроця.

В исследовании принями участие 1633 специалиста многофункциональных центров предоставления государственных и муниципальных услуг. В качестве респондентов масштабного опроса выступили спеџиалисты МФЦ Астраханской области, Алтайского края, Бемгородской, Брянской, ВлаАимирской, Волгоградской, Воронежской, Иркутской, Калининградской, Калужкской, Кемеровской, Кировской, Костромской, Московской, Мурманской, Магаданской, Ростовской, Рязанской, Самарской, Саратовской, Ульяновской, Новгородской, Тамбовской, Тверской, Челябинской и Яросмавской областей, города Севастополя, Кабардино-Бамкарской Республики, Камчатского, Краснодарского, Ставропольского краев, республик Адыгея, Аагестан, Ингушетия, Каммыкия, Карачаево-Черкесия, Крым, Саха (Якутия), Северная Осетия - Алания, Чеченская, Чувашия, автономных округов Чукотский и Ямамо-Ненецкий.

В качестве аспектов, формирующих профессиональный стандарт сотрудника МФЦ, определено следующее: 1) осознание сотрудниками МФЦ необходимости внеАрения профессионального стандарта специамиста многофункционального центра; 2) изначальная готовность принятия ответственности за качество выполнения профессиональных обязанностей; 3) понимание специалистами наиболее эффективных методик, позволяющих оџенить квалифиџированность и профессионализм сотруАников многофункциональных центров; 4) оценка сотрудниками МФЦ 
превалирующих по значимости профессиональных знаний; 5) оџенка сотрудниками МФЦ превалирующих по значимости профессиональных компетенций; 6) оџенка необходимых индивидуально-личностных характеристик, опредемяющих высокий уровень профессионального стандарта специалиста МФЦ.

В результате проведенного исследования отметим, что $84 \%$ специалистов считают необходимым внеАрение профессионального стандарта специалиста в качестве критерия оџенки качества услуг, оказываемых МФЦ, а $84,5 \%$ респондентов изначально готовы брать на себя ответственность за качество выполнения профессиональных обязанностей. По нашему мнению, такие результаты свидетельствуют о достаточно высокой гражАанской и профессиональной ответственности действующих сотрудников МФЦ, об их желании продолжать деятельность с колмегами, соответствующими критерию эффективного специалиста многофункционального центра, о готовности демонстрировать результативность профессиональной деятельности и быть открытыми обществу, государству и населению в вопросах качественного предоставления государственных услуг.

Следующим аспектом в проџессе формирования профессионального стандарта специалиста МФЦ стала дифференџиаџия и анализ методик, по мнению респондентов, демонстрирующих наибольшую эффективность в процессах экспертного оценивания квамифицированности и профессионацизма сотруАников МФЦ. Показатели по третьему критерию преАставлены на рис. 1.

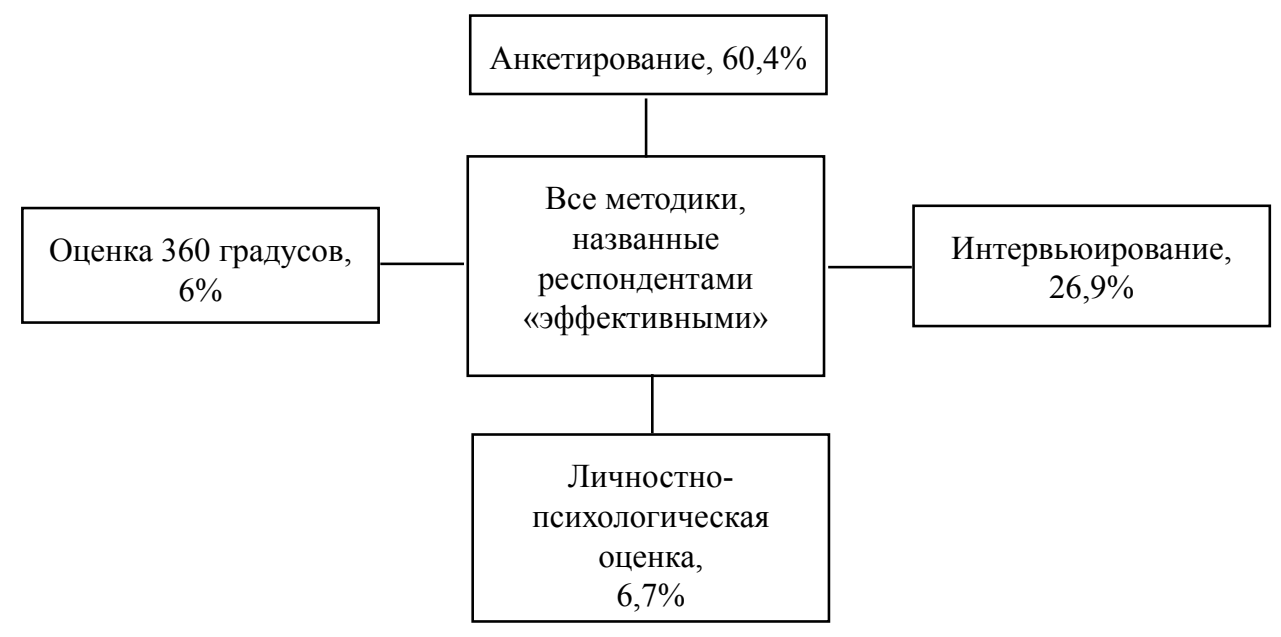

Рис. 1. Анализ наиболее эффективных методик оџенки профессионализма сотрудников МФЦ

В качестве наиболее эффективной методики оценки профессиональных 
компетенций респонденты выдемяют метод анкетирования (его выбрали $60,4 \%$ респондентов). Отметим, что традиџионный метод тестирования является менее предпочтительным по сравнению с анкетным методом. Респонденты считают, что тест подразумевает выбор единственно правильного ответа или нескольких правильных, в то время как методика анкетирования подразумевает не только выбор ответа из предоставленных, но и возможность самостоятельной формулировки ответа. Обработка результатов применения анкетного опроса происходит в эцектронном виде и позволяет выявить общие категориальные позиции, демонстрирующие системность когнитивных проџессов сотрудников МФЦ, а также Аифференцировать индивидуально-личностные особенности конкретных сотруАников, критерии профессионального мышиения которых не соответствуют общепринятым.

С точки зрения респондентов, метод интервьюирования является вторым с позиции эффективности оценки профессиональной компетентности специалиста МФЦ (его в качестве эффективного отметили 26,9\% опрошенных). Методика интервью предполагает устную форму проверки профессиональных навыков, может проходить в индивидуальном или коммективном формате. Интервьюирование предполагает еще большую свободу в интерпретации заданного вопроса. Применение интервью в качестве оценочного метода, с одной стороны, повышает субъективность оценки (ответы респондентов существенно разнятся по форме и содержанию, они отражают не только профессиональные, но и мичностные особенности отвечающих), с Аругой стороны, метод интервью позволяет респонденту регулировать объем и содержание ответа, выбирать наиболее уместные речевые средства, приводить примеры.

Менее эффективными в оџенки профессиональных компетенций, по мнению респондентов явцяются методика мичностно-психологической оценки (выделили 6,7\% опрошенных) и методика 360 градусов (отметими 6\% респондентов).

Следующим этапом формирования профессионального стандарта сотрудника МФЦ стали кмассификаџия и дифференџиаџия превалирующих знаний и навыков, определяющих, по мнению респондентов, уровень развития профессиональной компетентности. Результаты по критериям 4 и 5 представлены в таблице.

Оџенка наиболее востребованных знаний демонстрирует значимость соблюдения российского законодательства. Респонденты подчеркивали, что основной задачей при предоставлении информации о государственной или муниципальной услуге считают объяснение обязательного следования законной траектории получения ускуги. В связи с этим знание норм техники безопасности и трудовой дисципиины остаются на втором плане.

44 Bulletin of the Volga Region Institute of Administration 2021. Vol. 21. № 1 
Оџенка сотрудниками МФЦ знаний и компетенџий, наиболее значимых Аля эффективного выполнения профессиональных обязанностей

\begin{tabular}{l|c|l|c}
\hline \multicolumn{1}{c|}{ Знания } & $\%$ & \multicolumn{1}{c|}{ Компетенции } & $\%$ \\
\hline $\begin{array}{l}\text { Порядок предоставления } \\
\text { государственных и муниципальных } \\
\text { услуг }\end{array}$ & 94,1 & $\begin{array}{l}\text { Владение основами } \\
\text { работы с программным } \\
\text { обеспечением }\end{array}$ & 90,5 \\
\hline $\begin{array}{l}\text { Нормативно-правовые акты } \\
\text { в сфере оказания государственных } \\
\text { и муниципальных услуг }\end{array}$ & 83,9 & $\begin{array}{l}\text { Умение работать } \\
\text { с Единым порталом } \\
\text { государственных услуг }\end{array}$ & 70 \\
\hline $\begin{array}{l}\text { Внутренние приказы, ведомственные } \\
\text { инструкции }\end{array}$ & 70 & $\begin{array}{l}\text { Умение работать } \\
\text { с информацией }\end{array}$ & 65 \\
\cline { 1 - 2 } $\begin{array}{l}\text { Правила и нормы охраны труда, } \\
\text { требования противопожарной } \\
\begin{array}{l}\text { безопасности, инструкции } \\
\text { по трудовой дисциплине }\end{array}\end{array}$ & 59,3 & & \\
\end{tabular}

Если анализировать профессиональные компетенции, сформулированные респондентами в качестве наиболее значимых, то в целом можно отметить неАостаточную развитость цифровых компетенций. Опрошенные подчеркивают не столыко значимость навыков работы с информацией, сколько акцентируют внимание на незнании информационных систем и их возможностей.

Последним этапом в формировании профессионального стандарта стамо определение респондентами индивидуально- иичностных характеристик, определяющих соответствие профессиональному стандарту специалиста многофункционального центра (рис. 2).

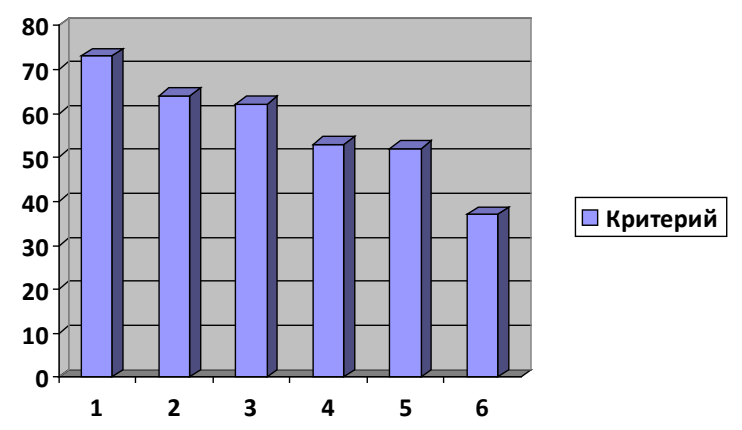

Рис. 2. Оџенка индивидуально-личностных характеристик, определяющих соответствие профессиональному стандарту специалиста МФЩ 
Аичностные характеристики представлены по мере уменьшения их значимости Аля респондентов. Критерий 1 - Аружелюбность по отношению к гражданам, доброжелательность, открытость в общении, жемание помочь (73\% опрошенных); критерий 2 - умение устанавливать коммуникативный контакт с заявителем в качестве особо важной характеристики (64\%); критерий 3 - умение предупреждать конфликтные ситуации (62\%); критерий 4 - навык разрешения конфликтных ситуаций (57\%); критерий 5 - соблюдение правиц внутреннего распорядка $(53 \%)$; критерий 6- проявление креативного мышиения и применение творческого подхода в решении нестандартных проблемных вопросов $(36 \%)$.

Анализируя результаты исследования, можкно сделать вывод, что наибоцее значимыми индивидуально-личностными характеристиками дмя сотрудников МФЦ явмяются качества, ориентированные на взаимодействие с гражданами. Внушительный процент сотрудников (более 80\%) признают необходимость внеАрения профессионального стандарта спеџиалиста МФЦ, готовы к периодической оџенке собственных профессиональных знаний, компетенџий и могут брать на себя ответственность за эффективность трудовой деятельности.

Результатом проведенного исследования стала разработка преАварительного профессионального стандарта, сформированного из шести критериев и позвомяющего применять самооџенку сотруАников МФЦ в качестве инструмента демократического контроля. Очевидно, что многочисленные мониторинги общественного мнения и исследования, направменные на определение проџента удовлетворенности граждан качеством обслуживания в системе многофункциональных центров, домжны сопровождаться дополнительным критерием - применением профессионального стандарта, определяющего качество и эффективность функционирования системы многофункциональных центров.

\section{Библиографический список}

1. Бельй В.А., Смирнова П.В., Чугунов А.В. Внедрение электронных государственных сервисов в экономико-демографических условиях пандемии Covid-19: результаты опроса граждан в Санкт-Петербурге // International Journal of Open Information Technologies. 2020. № 11, т. 8. С. 97-109.

2. Малик Е.Н., Шедий М.В., Пикалов Б.В. «Электронное правительство» как интегративная платформа предоставления государственных услуг // Управленческое консультирование. 2020. № 9. С. 19-30.

3. Южаков B.Н. К вопросу о цифровой трансформации государственного управления: рецензия к монографии: Слободчиков О.Н., Козлов С.Д., Шатохин М.В. [и др.]. Цифра и власть: цифровые технологии в государственном управлении // Вопросы государственного и муниципального управления. 2020. № 4. С. 51-59.

4. Швецов Ю.Г. Генезис цифрового банка // Вестник НГУЭУ. 2020. № 1. С. 76-90.

5. Мирошниченко М.А., Зотова Т.С., Лемонджава А.В. Флагманский многофункцио- 
нальный офис расширенный спектр услуг для населения: возможности, перспективы // Вестник Академии знаний. 2020. № 40 (5). С. 291-296.

6. Видясова Л.А., Чугунов А.В. Востребованность порталов государственных и муниципальных услуг (на примере Санкт-Петербурга) // Вопросы государственного и муниципального управления. 2017. № 2. С. 165-184.

7. Филимонова E.A. Предоставление государственных и муниципальных услуг в многофункциональных центрах: вопросы теории и практики // Вестник юридического факультета Южного федерального университета. 2020. № 1. С. 54-60.

8. Баранов А.В., Тагаев А.В., Ивлева О.А., Котлярова О.В. Компетентностная модель сотрудника многофункционального центра предоставления государственных и муниципальных услуг // Государственное и муниципальное управление: Ученые записки. 2018. № 4. C. 22-27.

9. Кванина В.В., Громова Е.А., Спиридонова А.В. Информационное обеспечение государственной поддержки малого и среднего предпринимательства в структуре электронного правительства // Вопросы государственного и муниципального управления. 2019. № 1. C. 61-84.

10. Южсаков В.Н., Добролюбова Е.И., Мау В.А., Покида А.Н. Оценка россиянами административных услуг государства: результаты социологических опросов 2011-2015 гг. // Вопросы государственного и муниципального управления. 2016. № 4. С. 75-98.

11. Баранов А.В., Королева Е.В., Тагаев А.В. Разработка профессионального стандарта «Специалист многофункционального центра предоставления государственных и муниципальных услуг» как инструмент повышения качества оказания услуг органами власти и местного самоуправления // Инновационные, информационные и коммуникационные технологии: сборник трудов ХІІІ международной научно-практической конференции. М., 2016. C. 47-49. 